\title{
Successful treatment of reactive airways dysfunction syndrome by high-dose vitamin D
}

\author{
This article was published in the following Dove Press journal: \\ Journal of Asthma and Allergy \\ 2I September 201 I \\ Number of times this article has been viewed
}

\author{
Veronica A Varney' \\ Jane Evans' \\ Amolak S Bansal ${ }^{2}$ \\ 'Department of Respiratory Medicine, \\ ${ }^{2}$ Department of Immunology and \\ Allergy, St. Helier Hospital, \\ Carshalton, Surrey, UK
}

Correspondence: Veronica A Varney St Helier Hospital, Wrythe Lane, Carshalton, Surrey SM5 IAA, UK

$\mathrm{Tel}+440208296240 \mathrm{l}$

$\mathrm{Fax}+4402082962733$

Email veronica.varney@esth.nhs.uk
Abstract: Reactive airways dysfunction syndrome is a controversial and poorly understood condition produced by inhalational injury from gas, vapors, or fumes. The symptoms mimic asthma, but appear unresponsive to asthma treatments. If symptoms persist for more than 6 months, there is a risk that they can become chronic. For these cases, effective treatments are lacking and quality of life is poor. We describe the first use of high-dose vitamin D in a patient with this condition, who fulfilled the 1995 American College of Chest Physicians criteria for this syndrome. The patient we describe presented an extremely difficult management problem and was refractory to conventional treatments, but responded to high-dose oral vitamin D supplements.

Keywords: asthma, vitamin D, reactive airways dysfunction syndrome, cough, inhalational injury

\section{Introduction}

Reactive airways dysfunction syndrome (RADS) is defined as the sudden onset of asthma-like symptoms following high-level exposure to a corrosive gas, vapor, or fumes. The term RADS was originally described by Brooks and Lockers in $1981^{1}$ as nonimmunological asthma resulting from exposure to an irritant gas. Given that most cases are recognized retrospectively, often with considerable delay, they usually lack accurate assessment of the exposure intensity and objective evidence of prior normal bronchial hyper-responsiveness required for the diagnosis of RADS. ${ }^{2}$

The symptoms usually manifest within 24 hours of exposure as bronchitis, with ocular or mucus membrane irritation of the upper airway (depending on the agent) and often require emergency treatment. The presentation of RADS is different from that of true occupational asthma, because it is an acute single event without a significant latency period. Many cases occurred after the 9/11 collapse of the New York World Trade Center, resulting from the inhalation of fumes and particulate matter. ${ }^{3}$ The American College of Chest Physicians consensus criteria for the diagnosis of RADS were agreed in $1995,{ }^{4}$ and were:

- Documented absence of preceding respiratory complaint

- Onset after single exposure incident/accident

- Exposure to very high concentration of gas, smoke, fumes, or vapors with irritant properties

- Onset of symptoms within 24 hours after exposure with persistence for at least 3 months 
- Symptoms that simulate asthma with cough, wheeze, and dyspnea

- Presence of airflow obstruction on pulmonary function \pm nonspecific bronchial hyper-responsiveness

- All other pulmonary disease excluded.

These criteria have been criticized for being overly restrictive by Alberts and do Pico. ${ }^{5}$ The pathology of RADS shows nonspecific inflammation, with a cellular infiltrate which is primarily lymphocytic with epithelial desquamation. ${ }^{6}$ Alberts and Brooks describe the "big bang" mechanism of epithelial injury, with activation of nonadrenergic and noncholinergic fibers via axon reflexes giving rise to neurogenic inflammation, macrophage activation, and mast cell degranulation. ${ }^{7}$ The resulting proinflammatory state, with toxic mediators, gives rise to epithelial injury. Although most people recover, extensive inflammation and epithelial sloughing could reduce receptor thresholds for severe ongoing bronchial hyper-reactivity. To date, there are no animal models of this disease. The literature suggests that RADS should be recognized as a unique form of asthma with significant upper airway symptoms that are often ignored but appear to be part of the condition. ${ }^{8}$ There is a growing list of recognized causal agents, ${ }^{9}$ which include:

- Household exposure: floor sealants, spray paint, bleaching agents, household cleaners containing morpholine.

- Chemical: chlorine, sulphuric acid, ammonia, hydrochloric acid, acetic acid, phosgene, hydrogen sulphide, sodium azide, sodium hypochlorite, toluene di-isocyanates, organic solvents.

- Industry: paint spraying, metal-coat removers, welding, heated plastics or acids, epoxy resins, perfumes, pesticides, enzymes, industrial cleaning products, dust or molds in silos.

- Other: Fire and smoke inhalation, burning paint fumes, tear gas, locomotive exhaust, World Trade Center collapse in New York.

There have been few developments in the management of this condition. Traditional treatment is the same as that of conventional asthma, despite evidence that patients with RADS are less responsive to $\beta_{2}$ agonists. ${ }^{10}$ Long-term outcome is not well documented, but if symptoms do not remit within 6-24 months they are more likely to become persistent. ${ }^{11}$ Oral corticosteroids and bronchodilators commenced within the first 3 months have had the most favorable outcomes. ${ }^{12,13}$ However, some reported case series suggest symptoms may be more persistent than originally thought. Demeter et al ${ }^{14}$ reported a nine-year follow-up, where nine of 19 patients with RADS still had ongoing symptoms, one of whom was progressive. Malo assessed mill workers following exposure to chlorine, and found that 29 of 51 still had bronchial hyper-responsiveness over a period of 24 months. ${ }^{15}$ There is a paucity of data regarding therapeutic interventions for those with persistent symptoms. The condition appears to have an equal male/female incidence. Nebulized sodium bicarbonate following chlorine gas exposure has been shown to improve quality of life and forced expiratory volume in 1 second $\left(\mathrm{FEV}_{1}\right),{ }^{16}$ but not lead to a resolution of symptoms. Lung transplantation has been used for severe ongoing symptoms of RADS following the New York World Trade Center collapse. ${ }^{17}$

This report describes a patient with severe unremitting symptoms of RADS five years following ammonia exposure, and discusses the response to vitamin $\mathrm{D}$.

\section{Case report}

A 36-year-old nursing sister was referred to our center with a history of incessant cough, shortness of breath, and extreme bronchial hyper-reactivity of five years' duration. Symptoms had started following exposure to an ammonia spillage by workmen on the floor below the renal unit where she worked as a dialysis sister. The unit had to be evacuated and she received high level exposure for up to two hours. Later that day she developed acute onset of cough, wheeze, and mucosal irritation symptoms, and needed to attend Accident and Emergency. There she was treated with nebulized salbutamol. Over a period of several days, the cough and wheeze worsened and she required prednisolone. Initially this produced an improvement in symptoms; however, over the subsequent year she required multiple courses of prednisolone, and commenced inhaled corticosteroids and a short-acting $\beta_{2}$ agonist. She was seen at a specialist chest hospital, but no solution or effective treatment was found, and pessimism developed about a likely response to any treatment.

Her original assessment showed normal routine blood tests, a clear chest radiograph, normal echocardiogram, and normal high-resolution computed tomography of her chest. Pulmonary function tests had revealed evidence of airways obstruction with airway resistance (raw) at $168 \%$ of predicted and reduced small airway indices. Lung volumes and gas transfer measurements were within normal limits. Histamine challenge was positive, with a methacholine-provoking concentration for a $20 \%$ fall $\left(\mathrm{PC}_{20}\right)$ of $7.3 \mathrm{mg} / \mathrm{mL}$.

The patient was unable to return to work, and had become virtually housebound due to the severity of her symptoms and the speed and intensity of her bronchospasm to outside 
odors. She had no prior respiratory illness, no atopy, and was a lifelong nonsmoker. Five years later, at the time of her referral to our center, her life quality was extremely poor. She was experiencing intractable paroxysms of coughing lasting continuously for 4-5 hours, with an incessant background cough leading to significant chest wall pain. She recognized multiple triggers, including air temperature changes, cigarette smoke, perfumes, cleaning products, exertion, and laughing. She suffered from dyspnea secondary to the coughing both at rest and on exertion due to her level of bronchial hyperreactivity. In terms of medication, she was taking high-dose inhaled Pulmicort ${ }^{\circledR}$, formoterol, ipratropium, and regular nonsteroidal anti-inflammatory analgesia and tramadol for chest wall pain, along with omeprazole. She would nebulize Ventolin ${ }^{\circledR}$ and Atrovent ${ }^{\circledR}$ according to need. She fulfilled all clinical criteria for the diagnosis of RADS. ${ }^{1}$

A repeat of her tests was impossible due to her intractable coughing. However, she did undergo a bronchoscopy at our center, which showed the entire bronchial tree mucosa to be deeply erythematous with widespread petechial hemorrhage. Due to the irritant effects of the disinfectants in the endoscopy suite, severe aggravation of her coughing occurred on her arrival, making the procedure very difficult, and precluding the chance of a biopsy.

She was commenced on prednisolone $60 \mathrm{mg}$ daily, along with her regular inhalers. Lidocaine nebulizers were trialed without therapeutic benefit. Inhaled sodium cromoglycate, oral antihistamines, and antileukotrienes were also tried without benefit. She subsequently received a trial of azithromycin and pulsed methylprednisolone also without benefit. Her total immunoglobulin $\mathrm{G}$ levels were below normal at $4.4 \mathrm{~g} / \mathrm{L}$ (normal range 6-16 g/L) without any other immune defect, and intravenous immunoglobulin $\left(\right.$ Vigam $\left.^{\circledR}\right)$ was given without benefit. Antiviral drugs were tried followed by cotrimoxazole without benefit, with trials lasting several weeks. It was then decided to try immunosuppression with cyclosporine. This appeared to increase her symptoms by 3 months, and at 4 months it was discontinued. This completed at least 12 months of trials with different treatments, without any hint of improvement.

At this stage, the immunological properties of vitamin D were being reported, and we began a trial of high-dose oral vitamin D 2000 IU/day. Vitamin D levels were requested, but her local hospital did not routinely perform this test. As a result, measurement at our hospital was arranged at her next visit. This showed a vitamin D level of $57 \mathrm{nmol} / \mathrm{L}$ at eight weeks after commencing the high dose. Scientific data from osteoporosis research shows a rise of 8-10 $\mathrm{nmol}$ each month on a vitamin D dose of $1000 \mathrm{IU} /$ day. This would suggest that our patient's vitamin D level was $<25 \mathrm{nmol} / \mathrm{L}$, initially consistent with severe deficiency. History-taking confirmed no ingestion of oily fish and no sunlight exposure or sunbathing for many years. At the start of vitamin D therapy, her symptoms were severe with incessant cough and bronchial hyper-reactivity as described before, which made measurement of formal lung function difficult. Her chest remained clear on physical examination, and she had a C-reactive protein of 0.2 and an immunoglobulin $\mathrm{E}$ of $9 \mathrm{kU} / \mathrm{L}$.

Despite no other adjustment to her regular medication regime, she noticed an improvement in her symptoms once her 25-hydroxyvitamin D blood levels were $>100 \mathrm{nmol} / \mathrm{L}$. Initially the paroxysms of cough abated, followed by resolution of dyspnea on exertion at vitamin D levels $>150 \mathrm{nmol} / \mathrm{L}$. We were then able to measure formal lung function tests reliably for the first time. Her vitamin D levels took 6 months to rise to $200 \mathrm{nmol} / \mathrm{L}$. At that point symptoms resolved, and weaning of nebulizers, steroids, nonsteroidal anti-inflammatory drugs, and other painkillers could commence, because chest wall pains due to incessant cough eased. Figure 1 demonstrates her serum vitamin D levels, and highlights the symptomatic improvement and spirometry.

At two years, the patient remains largely asymptomatic and is rebuilding her life. Her lung function tests one year later are normal (forced vital capacity $117 \%$, vital capacity $100 \%$, TLCO (transfer factor of the lung for carbon monoxide) $97 \%$, forced expiratory flow 25\%-75\% 110\%), apart from a residual volume of $182 \%$ of predicted which has remained unchanged on several repeat measurements. A recent methacholine test gave a $\mathrm{PC}_{20}$ of $32 \mathrm{mg} / \mathrm{mL}$.

High-dose vitamin D has been continued and blood levels have remained at 150-200 nmol/L with normal calcium levels. There are no reported adverse effects of regular vitamin D at doses of up to $5000 \mathrm{IU} /$ day. The current recommendation for adults is now $1000 \mathrm{IU} /$ day. There were no side effects of the vitamin $\mathrm{D}$, but oral preparations are known to have a mild laxative effect and increase skin oils that may cause spots.

\section{Discussion}

We all live or work in an increasingly chemical environment, where uncontrolled inhalational exposures to toxic materials could affect our respiratory system acutely. The risk of toxic household cleaning products, paints, and resins may not be well recognized by the general public, unlike that in industry where risk assessments are paramount. 


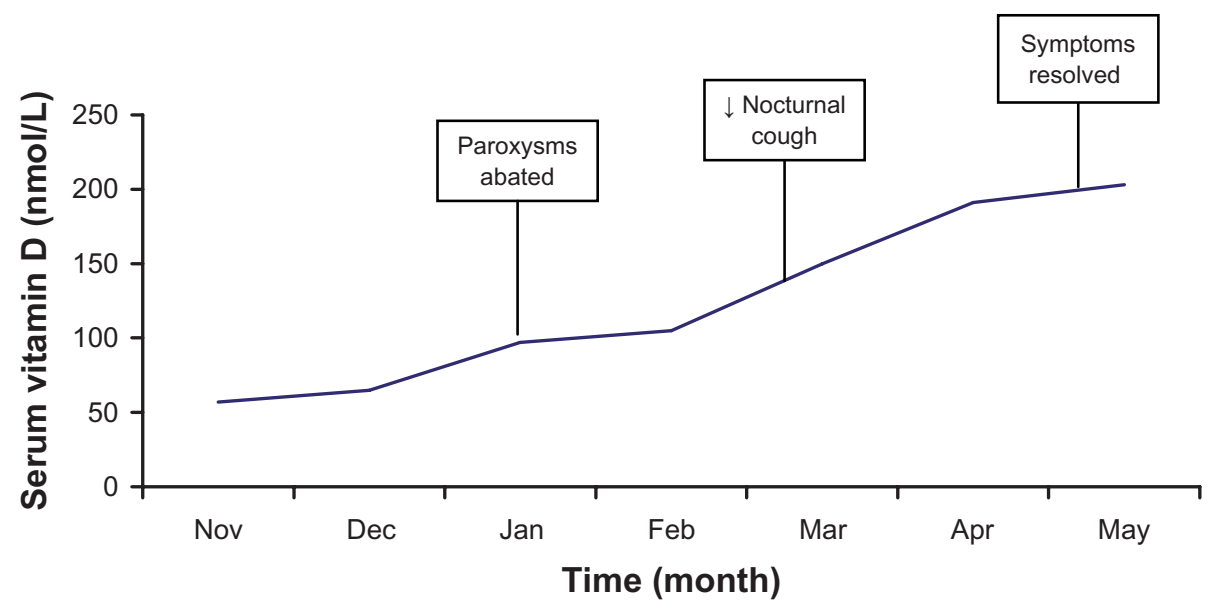

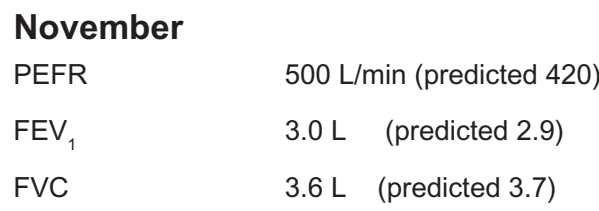

May

PEFR 600

$\mathrm{FEV}_{1} 3.5 \mathrm{~L}$

FVC $3.8 \mathrm{~L}$

Figure I Symptoms and serum vitamin D levels measured over the first 6 months of treatment.

Abbreviations: PEFR, peak expiratory flow rate; FEV , forced expiratory volume in I second; FVC, forced vital capacity.

RADS is a condition which currently lacks clarity, ${ }^{2,18}$ with the main difficulties related to retrospective diagnosis of a condition following an unmeasured exposure to a respiratory irritant. Animal models to establish the exact nature and natural history are still awaited, but should assist our understanding of whether this is an asthma variant or a different disease state. While the literature contains increasing numbers of reported cases from an expanding array of causal agents, it lacks any guidance on effective treatment, especially for those patients with ongoing symptoms who have a very poor quality of life.

The effects of vitamin $\mathrm{D}$ as a hormone have gained attention in the literature over the last 2-3 years. Vitamin D appears to have regulatory effects on every part of the immune system, with vitamin D deficiency being linked to an array of immunologically based diseases. ${ }^{19}$ Because Vitamin D promotes steroid sensitivity in the body and can downregulate an inflammatory state via gene expression and cytokine production, its action in this case could be directly on the airway. Vitamin D receptors are present in the airways and are thought to inhibit proinflammatory cytokines, with effects on CD4+ T cells, interleukin-2, interferon-gamma, and macrophages..$^{20,21}$ A deficiency of Vitamin D could be associated with an inability to switch off the inflammatory state, following an acute inhalational insult, with upregulation of prostaglandin, leukotrienes, macrophages, and $\mathrm{T}$ cell activity and recruitment. Vitamin D receptor polymorphisms are gaining attention as a cause of vitamin D insensitivity in respiratory diseases, which can be overcome by high doses. In our case, vitamin D deficiency was present because optimal blood levels should be $>75 \mathrm{nmol} / \mathrm{L}$. Recent data suggests higher values $(>150 \mathrm{nmol} / \mathrm{L})$ are needed for optimal immune health.

We had no histological biopsies from our case, but considered her to fulfill all criteria for RADS. This case presented a difficult management problem, and was refractory to all conventional treatments, with devastating effects on employment. The responses to vitamin D were slow and progressive, and effects appeared optimal when blood levels were $>150 \mathrm{nmol} / \mathrm{L}$. These observations would support a trial of high-dose oral vitamin D in similar cases of RADS refractory to asthma treatment. If this experience is repeated, it may assist our understanding of the condition and possible disease mechanisms, via the anti-inflammatory effects of vitamin $\mathrm{D}$, and offer a treatment.

\section{Disclosure}

The authors report no conflicts of interest in this work.

\section{References}

1. Brooks SM, Lockers J. Reactive airways dysfunction syndrome: A newly diagnosed occupational disease. Am Rev Respir Dis. 1981;123 (Suppl 1):A133.

2. Bardana EJ. RADS guidelines for diagnosis and treatment and insight into likely prognosis. Ann Allergy Asthma Immunol. 1999;83:583-586.

3. Banauch GI, Alleyne D, Sanchez R, et al. Persistent hyper-reactivity and RADS in fire fighters at the World Trade Center. Am J Respir Crit Care Med. 2003;168:54-62. 
4. Chan Yeung M. Assessment of asthma in the workplace. Chest. 1995; 108:1084-1117.

5. Alberts WM, do Pico GA. Reactive airways disease syndrome. Chest. 1995;109:1618-1626.

6. Lemiere C, Malo JC, Bould L, et al. RADS induced by exposure to a mixture of isocyanate: Functional and histopathologic behaviour. Allergy. 1996;51:262-265.

7. Alberts WM, Brooks SM. Advances in occupational asthma. Clin Chest Med. 1992;13:281-302.

8. Brooks SM, Weiss MA, Benstein IL. Reactive airways dysfunction syndrome (RADS): Persistent asthma syndrome after high-level irritant exposure. Chest. 1985;88:376-384.

9. Shakeri MS, Dick FD, Ayres JG. Which agents cause reactive airways dysfunction syndrome (RADS)? A systematic review. Occup Med. 2008;58:205-211.

10. Gautrin D, Boulet LP, Boulet M, et al. Is reactive airways dysfunction syndrome a variant of occupational asthma? J Allergy Clin Immunol. 1994; $93: 12-22$.

11. Tarlo SM, Banks D, Liss G, et al. Asthma related to spills and accidental irritant exposures in a compensation population. Am J Respir Crit Care Med. 1995;151 Suppl:A420.

12. Alberts WM, do Pico GA. Reactive airways dysfunction syndrome. Chest. 1996;109:1618-1626.

13. Alberts WM, Brooks SM. Reactive airways dysfunction syndrome. Curr Opin Pulm Med. 1996;2:104-110.
14. Demeter SL, Cordasco EM, Guidotti TC. Permanent respiratory impairment and upper airways symptoms despite clinical improvement in patients with RADS. Sci Total Environ. 2001;270: $49-55$.

15. Malo JL, Carlier A, Boulet LP, et al. Bronchial hyperresponsiveness can improve while spirometry plateaus $2-3$ yrs after repeated exposures to chlorine causing respiratory symptoms. Am J Respir Crit Care Med. 1994;150:1142-1145.

16. Asla S, Kandis H, Akgun M, Cakir Z, Inandi T, Görgüner M. The effect of nebulised $\mathrm{NaHCO}_{3}$ on RADS due to chlorine gas inhalation. Inhal Toxicol. 2006;18:895-900.

17. Banauch GI, Dhala A, Alleyne D, et al. Bronchial hyperreactivity and other inhalational lung injuries in rescue/recovery workers after the World Trade Center collapse. Crit Care Med. 2005;33 Suppl 1: S102-S106.

18. Bardana EJ. Occupational asthma and related respiratory disorders. Dis Mon. 1995;16:141-200.

19. Contorna MT, Mahon BD. Mounting evidence for Vitamin D as an environmental factor affecting autoimmune disease prevalence (review). Exp Biol Med. 2004;229:1136-1147.

20. Mullin BE, Dobs A. Vitamin D and its role in cancer and immunity: A prescription for sunlight. Nutr Clin Pract. 2007;22:305-322.

21. Litonjua AA, Weiss ST. Is vitamin D deficiency to blame for the asthma epidemic. J Allergy Clin Immunol. 2007;120:1031-1035.
Journal of Asthma and Allergy

\section{Publish your work in this journal}

The Journal of Asthma and Allergy is an international, peer-reviewed open-access journal publishing original research, reports, editorials and commentaries on the following topics: Asthma; Pulmonary physiology; Asthma related clinical health; Clinical immunology and the immunological basis of disease; Pharmacological interventions and

\section{Dovepress}

new therapies. Issues of patient safety and quality of care will also be considered. The manuscript management system is completely online and includes a very quick and fair peer-review system, which is all easy to use. Visit http://www.dovepress.com/testimonials.php to read real quotes from published authors. 